Y. Yamaguchi, MD

H. Torisu, BS, MD, PhD

R. Kira, MD, PhD

Y. Ishizaki, MD, $\mathrm{PhD}$

Y. Sakai, MD, PhD

M. Sanefuji, MD, PhD

T. Ichiyama, MD, PhD

A. Oka, MD, $\mathrm{PhD}$

T. Kishi, MD, PhD

S. Kimura, MD, $\mathrm{PhD}$

M. Kubota, MD, PhD

J. Takanashi, MD, PhD

Y. Takahashi, MD, PhD

H. Tamai, MD, PhD

J. Natsume, MD, PhD

S. Hamano, MD, PhD

S. Hirabayashi, MD, PhD

Y. Maegaki, MD, PhD

M. Mizuguchi, MD, PhD

K. Minagawa, MD, PhD

H. Yoshikawa, MD, PhD

J. Kira, MD, PhD

S. Kusunoki, MD, PhD

T. Hara, MD, PhD

Correspondence to

Dr. Torisu:

htorys@pediatr.med.kyushu-u.ac.

jp

Supplemental data at Neurology.org

\title{
A nationwide survey of pediatric acquired demyelinating syndromes in Japan OPEN
}

ABSTRACT

Objective: To investigate the clinical and epidemiologic features of pediatric acquired demyelinating syndromes (ADS) of the CNS in Japan.

Methods: We conducted a nationwide survey and collected clinical data on children with ADS aged 15 years or younger, who visited hospitals between 2005 and 2007.

Results: Among 977 hospitals enrolled, 723 (74.0\%) responded to our inquiries and reported a total of 439 patients as follows: 244 with acute disseminated encephalomyelitis (ADEM), 117 with multiple sclerosis (MS), 14 with neuromyelitis optica (NMO), and 64 with other ADS. We collected and analyzed detailed data from 204 cases, including those with ADEM (66), MS (58), and NMO (10). We observed the following: (1) the estimated annual incidence rate of pediatric ADEM in Japan was 0.40 per 100,000 children (95\% confidence interval [CI], 0.34-0.46), with the lowest prevalence in the north; (2) the estimated prevalence rate of MS was 0.69 per 100,000 children $(95 \% \mathrm{Cl}, 0.58-0.80)$, with the lowest prevalence in the south; (3) NMO in Japan was rare, with an estimated prevalence of 0.06 per 100,000 children $(95 \% \mathrm{Cl}, 0.04-$ 0.08 ); and (4) the sex ratio and mean age at onset varied by ADS type, and (5) male/female ratios correlated with ages at onset in each ADS group.

Conclusions: Our results clarify the characteristic clinical features of pediatric ADS in the Japanese population. Neurology ${ }^{\circledast}$ 2016;87:2006-2015

\section{GLOSSARY:}

ADEM = acute disseminated encephalomyelitis; $\mathbf{A D S}=$ acquired demyelinating syndrome; $\mathbf{A Q P 4}=$ aquaporin- $4 ; \mathbf{C I}=$ confidence interval; CIS = clinically isolated syndrome; IgG = immunoglobulin G; IPMSSG = International Pediatric Multiple Sclerosis Study Group; $\mathbf{M D E M}=$ multiphasic disseminated encephalomyelitis; $\mathbf{M S}$ = multiple sclerosis; $\mathbf{N M O}=$ neuromyelitis optica; RDEM = recurrent disseminated encephalomyelitis.

Acquired demyelinating syndromes (ADS) are clinical CNS events with presumed immunemediated inflammatory demyelinating causes. They are classified into several clinical entities based on lesion location and disease time course, including multiple sclerosis (MS), acute disseminated encephalomyelitis (ADEM), variants of ADEM associated with repeat episodes, neuromyelitis optica (NMO), and clinically isolated syndrome (CIS) including optic neuritis and myelitis. ${ }^{1}$ Variable signs of onset and time courses of ADS may hamper early diagnosis and identification of the specific ADS category at the first demyelination episode. Thus, a number of

From the Department of Pediatrics (Y.Y., H. Torisu, R.K., Y.I., Y.S., M.S., T.H.) and Department of Neurology, Neurological Institute (J.K.), Graduate School of Medical Sciences, Kyushu University, Fukuoka; Department of Pediatrics (H. Torisu), Fukuoka Dental College Medical and Dental Hospital, Fukuoka; Department of Pediatrics (T.I.), Yamaguchi University Graduate School of Medicine, Ube; Department of Pediatrics (A.O.), Kyorin University School of Medicine, Hachioji; Department of Pediatrics (T.K.), Tokyo Women's Medical University, Tokyo; Department of Child Development Pediatrics (S. Kimura), Kumamoto University Graduate School, Kumamoto; Division of Neurology (M.K.), National Center for Child Health and Development, Tokyo; Department of Pediatrics (J.T.), Kameda Medical Center, Kamogawa; National Epilepsy Center (Y.T.), Shizuoka Institute of Epilepsy and Neurological Disorders, Shizuoka; Department of Pediatrics (H. Tamai), Osaka Medical College, Takatsuki; Department of Pediatrics (J.N.), Nagoya University Graduate School of Medicine, Nagoya; Department of Neurology (S. Hamano), Saitama Children's Medical Center, Saitama; Department of Neurology (S. Hirabayashi), Nagano Children's Hospital, Azumino; Division of Child Neurology (Y.M.), Faculty of Medicine, Tottori University, Yonago; Department of Developmental Medical Sciences (M.M.), Graduate School of Medicine, The University of Tokyo; Department of Pediatrics (K.M.), Hokkaido Medical Center for Child Health and Rehabilitation, Sapporo; Department of Pediatric Neurology (H.Y.), Nagaoka Habilitation and Medical Center for Severely Handicapped Children, Nagaoka; and Department of Neurology (S. Kusunoki), Kinki University Faculty of Medicine, Osaka-Sayama, Japan.

Go to Neurology.org for full disclosures. Funding information and disclosures deemed relevant by the authors, if any, are provided at the end of the article. The Article Processing Charge was paid by the authors.

This is an open access article distributed under the terms of the Creative Commons Attribution-NonCommercial-NoDerivatives License 4.0 (CC BY-NC-ND), which permits downloading and sharing the work provided it is properly cited. The work cannot be changed in any way or used commercially. 
studies have been conducted to identify ADS subgroups based on their initial symptoms and clinical profiles. ${ }^{2-7}$ Diagnosing ADS in childhood is more difficult than in adulthood. ${ }^{8}$ Recent studies have described the epidemiologic and clinical features of child-onset ADS in Europe and the United States; however, such findings are not always consistent across studies with different populations. ${ }^{4,6,7,9-12}$ Considering that few cases of Asian patients with pediatric ADS have been reported, ${ }^{13-19}$ we conducted the first nationwide survey for pediatric ADS in Japan. Our results clarify the demographic features of pediatric ADS in an Asian population and highlight the differences among regions and ethnic groups.

METHODS Survey procedure. A nationwide survey for pediatric ADS was conducted from 2008 to 2009 in Japan (figure e- 1 at Neurology.org). The data were collected according to the previously described methods. ${ }^{20,21}$ Pediatric patients in Japan with ADS or suspected ADS seen in clinics are usually referred to tertiary hospitals that they visit on a regular basis. The target patients were those who visited the pediatric departments of hospitals in Japan between January 1, 2005 , and December 31, 2007, for pediatric ADS: ADEM, recurrent disseminated encephalomyelitis (RDEM), multiphasic disseminated encephalomyelitis (MDEM), CIS, NMO, and MS. The hospitals were selected from among all registered hospitals with pediatric departments in Japan according to the Nationwide Epidemiological Survey Manual of Patients with Intractable Diseases (2nd edition 2006, Ministry of Health, Labour and Welfare of Japan). The 977 hospitals considered for the current study included 551 tertiary hospitals and 426 randomly selected hospitals according to stratification based on the number of beds (table e-1). We sent all the selected hospitals questionnaires requesting the numbers of target patients who met the diagnostic criteria of the above-mentioned diseases. A second questionnaire concerning the detailed clinical features of each patient was sent to all hospitals that responded and had treated one or more patients with ADS. We requested whether the

\begin{tabular}{|c|c|c|c|c|c|}
\hline \multirow[t]{2}{*}{ Table 1} & \multicolumn{5}{|c|}{ Estimated incidence and prevalence of ADS in Japan, 2005-2007 } \\
\hline & $\begin{array}{l}\text { Reported } \\
\text { patients } \\
\text { between 2005- } \\
2007, \mathrm{n}\end{array}$ & $\begin{array}{l}\text { Estimated } \\
\text { patients } \\
\text { between 2005- } \\
2007, \mathrm{n}\end{array}$ & $\begin{array}{l}\text { Estimated } \\
\text { incidence, } \\
\text { /100,000 } \\
\text { children }\end{array}$ & $\begin{array}{l}\text { Estimated } \\
\text { prevalence, } \\
/ 100,000 \\
\text { children }\end{array}$ & $95 \% \mathrm{Cl}$ \\
\hline ADEM & 216 & 226 & 0.40 & NA & $0.34-0.46$ \\
\hline MS & 101 & 129 & NA & 0.69 & $0.58-0.80$ \\
\hline NMO & 8 & 11 & NA & 0.06 & $0.04-0.08$ \\
\hline MDEM & 8 & 11 & NA & 0.06 & $0.04-0.08$ \\
\hline RDEM & 7 & 10 & NA & 0.05 & $0.03-0.07$ \\
\hline
\end{tabular}

Abbreviations: $A D E M=$ acute disseminated encephalomyelitis; $A D S=$ acquired demyelinating syndrome; $\mathrm{Cl}=$ confidence interval; $\mathrm{MDEM}=$ multiphasic disseminated encephalomyelitis; $\mathrm{MS}=$ multiple sclerosis; $\mathrm{NA}=$ not available; $\mathrm{NMO}=$ neuromyelitis optica; $\mathrm{RDEM}=$ recurrent disseminated encephalomyelitis. pediatricians in the facilities could provide detailed clinical information on individual patients based on their medical records (appendix e-1). The clinical data for all patients were reviewed based on diagnostic criteria established by boardcertified pediatric neurologists (Y.Y., H. Torisu, and R.K.). We excluded patients who did not meet any diagnostic standard and who had the first demyelinating episode after 15 years of age. We also excluded duplicate cases. Based on the selection rate, the survey response rate, and the result of the secondary survey, we estimated the number of patients with each pediatric ADS according to previously described methods ${ }^{20,21}$ and the 2005 national census in which the total population in Japan was a reported 128 million with 17.5 million younger than 16 years.

Pediatric ADS diagnosis. We followed definitions proposed by the International Pediatric Multiple Sclerosis Study Group (IPMSSG), including diagnostic criteria for ADEM, RDEM, MDEM, and CIS. ${ }^{1}$ For MS, we applied the standard criterion, 2 discrete demyelinating clinical events, used for diagnosis of clinically definite MS. Finally, we used the 2006 NMO criteria to diagnose $\mathrm{NMO}^{22}$

Statistical analysis. Statistical analyses were performed using JMP 6.0.3 (SAS Institute, Inc., Cary, NC). Descriptive data were compared using $\chi^{2}$ or Fisher exact tests for ratios and MannWhitney $U$ tests for numerical variables.

Standard protocol approvals, registrations, and patient consents. This study was performed as a project study in the Research Committee of Neuroimmunologic Diseases, under the auspices of the Ministry of Health, Labour and Welfare of Japan. This study was approved by the institutional review board at Kyushu University (\#20-64) and stringently performed according to their guidelines.

RESULTS We received responses from 723 of the 977 hospitals (74.0\%) initially nominated. Among them, 183 treated one or more patients with pediatric ADS during the 3-year surveillance period. The total number of reported patients during the surveillance period was 439 (61 suspected cases), including 244 patients with ADEM (28), 9 with RDEM (2), 12 with MDEM (4), 43 with CIS (5), 117 with MS (16), and 14 with NMO (6) (table e-1).

In the second survey, 134 of the 178 hospitals (74.9\%) provided detailed information regarding the clinical profiles of 250 patients, including suspected cases. The response bias was limited because the response rates did not differ according to hospital size or location. After extensive review by certified pediatric neurologists, we excluded patients who did not meet the diagnostic criteria or who were duplicates. Thus, we analyzed data for 66 patients with ADEM, 2 with RDEM, 7 with MDEM, 61 with CIS (39 with multifocal CIS, 11 with myelitis, and 11 with optic neuritis), 58 with MS, and 10 patients with NMO.

Epidemiologic features. The results of the first survey showed that ADEM was the most common clinical entity among pediatric ADS, whereas NMO and ADEM variants were less prevalent. After adjustment 
Figure 1 Japanese regions investigated in the survey

\begin{tabular}{lccc} 
A. ADEM & $\begin{array}{c}\text { Estimated } \\
\text { population } \\
\text { Area }\end{array}$ & $\begin{array}{c}\text { Estimated patients } \\
\text { in } 3 \text { years, } n\end{array}$ & $\begin{array}{c}\text { Estimated annual } \\
\text { incidence } \\
\left(/ 10^{5} \text { children }\right)\end{array}$ \\
\hline Northern & 2,551 & 22 & 0.287 \\
Central & 12,190 & 166 & 0.454 \\
Southern & 4,031 & 39 & 0.323 \\
\hline Total & 18,772 & 227 & 0.403
\end{tabular}

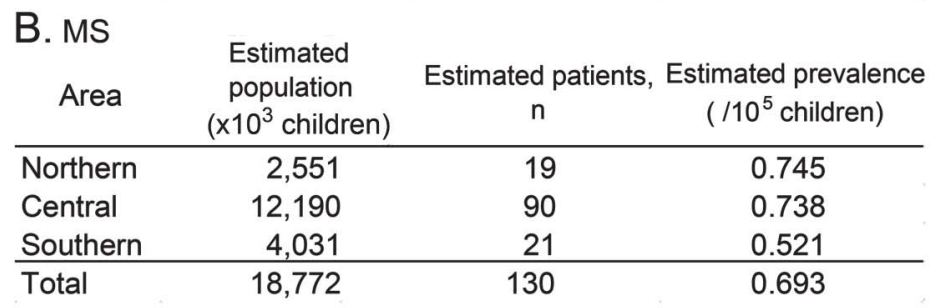

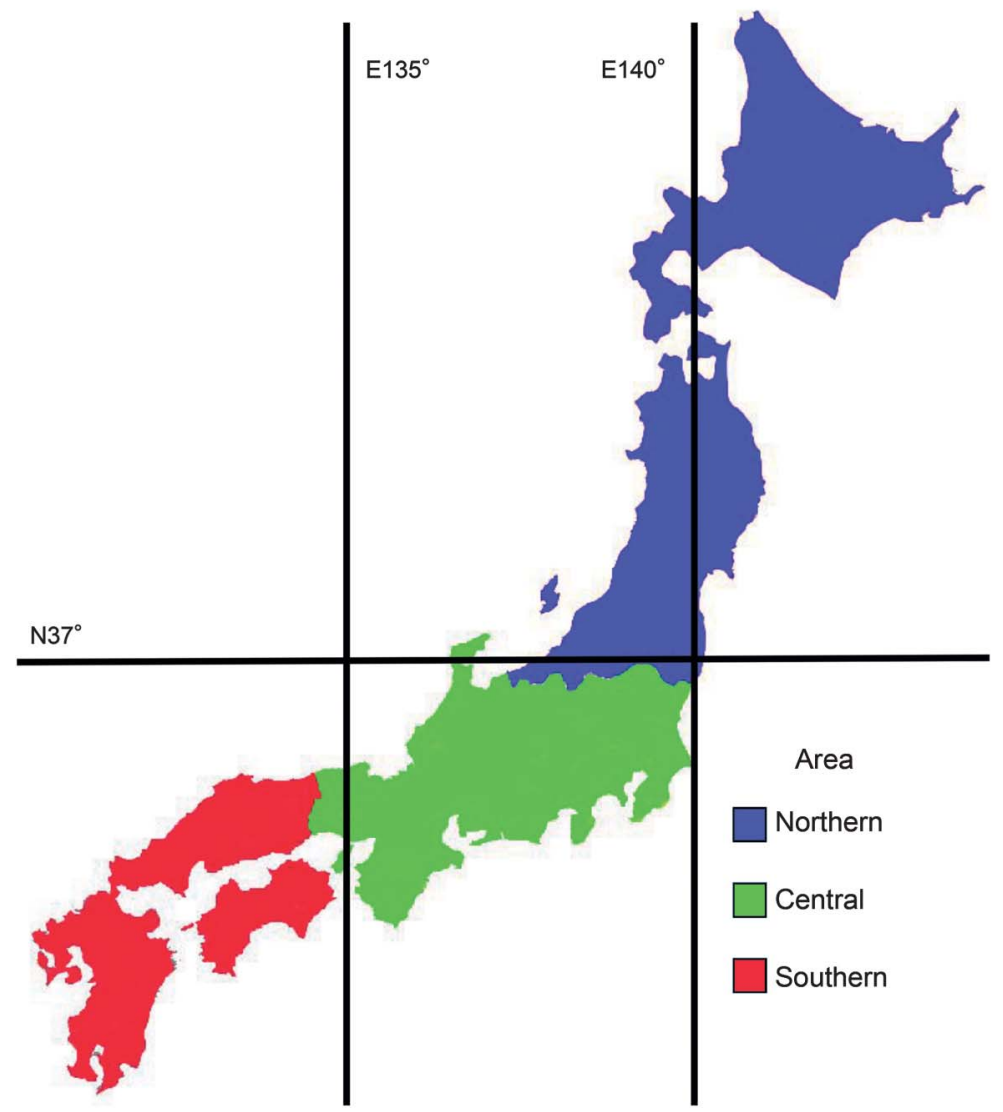

Japan is divided into 3 areas by the 37 th parallel north and the 135 th meridian east. (A) ADEM, (B) MS. ADEM = acute disseminated encephalomyelitis; $M S$ = multiple sclerosis.

based on the results of the secondary survey, there were an estimated 226 (95\% confidence interval [CI], 191-260) pediatric patients with ADEM during the 3-year surveillance period, with an annual estimated incidence based on the national census of 0.40 per 100,000 children (95\% CI, 0.34-0.46) (table 1). The incidence of ADEM in northern Japan tended to be lower than that in the central and southern regions $(p=0.09)$ (figure 1). There were an estimated 129 (95\% CI, 108-150) pediatric patients with MS, with an estimated prevalence of 0.69 per 100,000 children $(95 \% \mathrm{CI}$, $0.58-0.80)$. The prevalence rate of MS in southern Japan tended to be lower than that in the central and northern areas of Japan ( $p=0.14)$. NMO was rarely diagnosed: there were an estimated 11 patients $(95 \%$ CI, 7-14), with an estimated prevalence of 0.06 per 100,000 children (95\% CI, 0.04-0.08).

Demographic features. The results of the second survey showed that the sex ratio and mean age at onset varied among pediatric patients with ADS. Specifically, diseases with younger mean ages at onset tended to have higher male/female ratios (figure 2). Patients with ADEM had the youngest mean age at onset ( 5.5 years) and the lowest female/male ratio (33.3\%). In contrast, patients with $\mathrm{NMO}$ had the oldest mean age at onset (10.3 years) and the highest female/male ratio $(80.0 \%)$.

Signs and symptoms. As shown in table 2, there was no apparent difference in the ratio of patients with ADEM and multifocal CIS who had experienced preceding infection (62\% vs $59 \%$ ). Furthermore, $18 \%$ of patients with ADEM and $10 \%$ of those with CIS received vaccinations in the month before the disease onset. The prevalence of pyrexia preceding neurologic symptoms was similar in patients with ADEM and multifocal CIS ( $68 \%$ vs $77 \%$ ).

No significant differences in the incidence of seizures at the time of onset were observed between patients with ADEM and those with MS (32\% vs $29 \%$ ), but gait and urinary disturbances occurred more frequently in patients with ADEM than in patients with MS (first event) (59\% vs $26 \%$ and $24 \%$ vs 5\%; $p<0.001$ and $p=0.003$, respectively). In addition, visual loss occurred less frequently in patients with ADEM than in patients with MS (first event) $(11 \%$ vs $52 \%$ : $p<0.001)$.

Laboratory findings. A high percentage of patients with pediatric ADS also demonstrated pleocytosis: $85 \%$ of patients with ADEM, $82 \%$ with multifocal CIS, $71 \%$ with MS, and $100 \%$ with NMO (table 2). A low percentage of patients exhibited increasing immunoglobulin $\mathrm{G}$ ( $\mathrm{IgG}$ ) indexes: $36 \%$ of those with ADEM, 27\% with multifocal CIS, 29\% with MS, and none of the patients with NMO. Intrathecal synthesis of oligoclonal bands was detected in small numbers of patients (table 2). NMO-IgG was detected in 1 of the 12 patients with MS and 3 of the 6 patients with NMO.

MRI findings. The mean numbers of cerebral lesions did not differ significantly among patients with ADEM (6.3), multifocal CIS (4.8), and MS (5.7) (table 2). Optic nerve lesions were less frequent in 


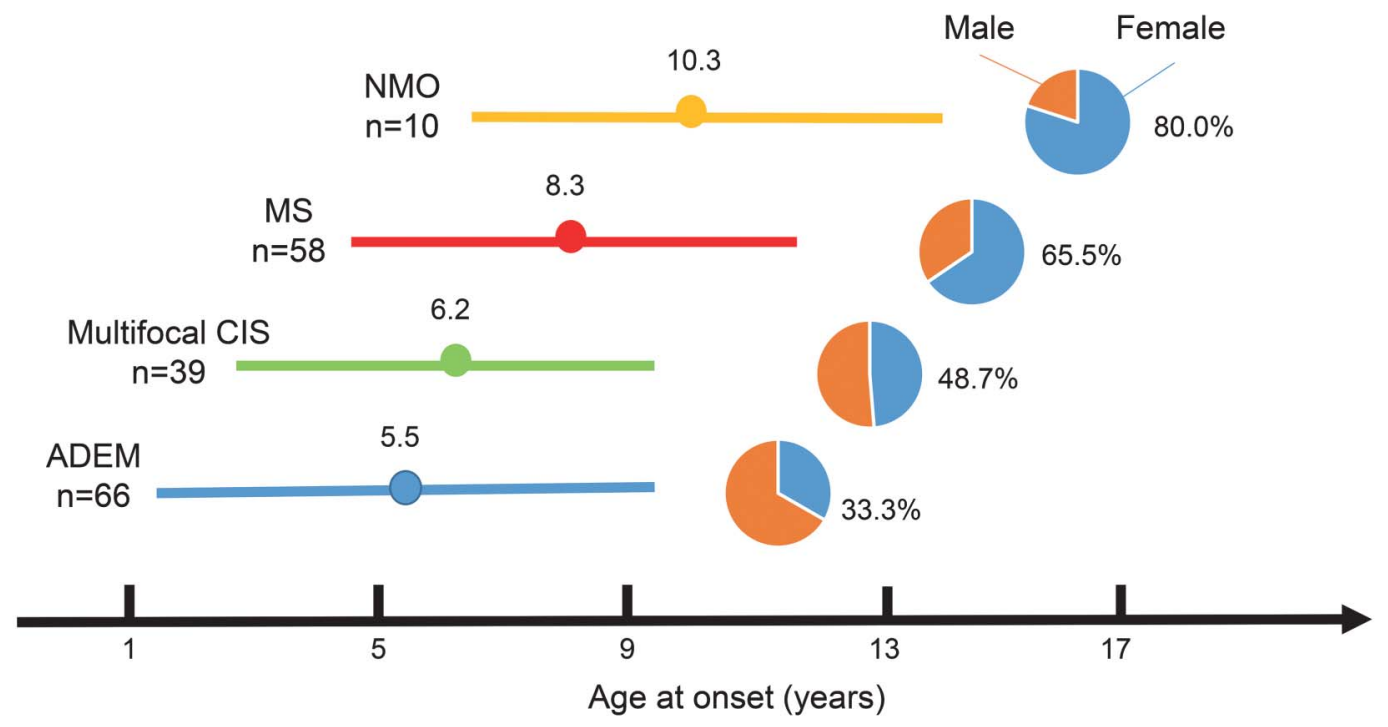

Age at onset (mean $\pm 1 \mathrm{SD}$ ) and female/male ratios are shown for each disease. Diseases with younger mean ages at onset tended to have lower female/male ratios. ADEM = acute disseminated encephalomyelitis; CIS = clinically isolated syndrome; MS = multiple sclerosis; NMO = neuromyelitis optica.

patients with ADEM (6.5\%) than in those with multifocal CIS (15\%) and MS (35\%). Brainstem lesions were observed in $29 \%$ of patients with ADEM, $44 \%$ with multifocal CIS, and 36\% with MS. Among cases of NMO, 9 of 10 patients had cerebral lesions (mean number of lesions: 3.0). The lesions were widely scattered in the CNS, similar to the distribution in the other diseases (table 2).

Treatments and outcomes. In the acute phase, most patients with pediatric ADS were treated with immunosuppressive therapy, including IV highdose methylprednisolone, oral steroids, and IV immunoglobulin. In the remission phase, 19 patients with MS (33\%) were treated with interferonbeta (table 2). Three patients experienced disease exacerbation after interferon beta treatment. Twentytwo patients (38\%) with MS were treated; 5 patients (50\%) with NMO were treated with oral steroids, one (10\%) with IV immunoglobulin and 4 (40\%) with immunosuppressants. Five patients $(50 \%)$ were treated with interferon beta: 4 with $\mathrm{Ib}$ and one with both Ia and Ib. One patient experienced disease exacerbation after interferon beta treatment.

The mean Expanded Disability Status Scale scores of patients with all the diseases were low: 0.29 for ADEM, 0.4 for multifocal CIS, 1.1 for MS, and 1.6 for NMO. The annualized relapse rates were 0.82 and 0.70 times per year for MS and NMO, respectively.

DISCUSSION This nationwide survey elucidated the current status of pediatric ADS in Japan. ADEM, the most common pediatric ADS in Japan, was mostly diagnosed in preschool-age children, without a sex predilection. In contrast, MS and NMO occurred more commonly in female patients and older children. Multifocal CIS had distinct features from ADEM and MS in most aspects. These demographic features of pediatric ADS in Japan were largely similar to those reported in previous studies in other countries, but there were some unique differences.

Pediatric ADEM in Japan. We estimated the crude annual incidence of pediatric ADEM in Japan as 0.40 per 100,000 children, which is similar to the 0.60 per 100,000 children reported for Fukuoka, Japan. ${ }^{17}$ Four epidemiologic studies reported the following incidences of pediatric ADEM: 0.07 per 100,000 children in Germany, ${ }^{10} 0.2$ in Canada, ${ }^{4}$ 0.4 in San Diego in the United States, ${ }^{9}$ and 0.4 in southern California in the United States. ${ }^{7}$ In the present study, the estimated ADEM incidence was lower in northern Japan compared to central and southern areas of the country, suggesting that regional and ethnic backgrounds may affect the incidence of pediatric ADEM.

We also found that patients with ADEM exhibited gait and urinary disturbances more frequently and visual loss less frequently than patients with MS at the first demyelinating event. This result is consistent with the result from a French study, which reported that children with only one demyelinating event had a higher rate of myelitis than those with 2 or more events. ${ }^{2}$ Moreover, the result regarding 
Table 2 Clinical characteristics of pediatric acquired demyelinating syndromes in Japan

\section{Male/female ratio}

History, n (\%)

\section{Allergy}

\section{Fever}

Rash

Mean age at onset, \pm SD, $y$

Follow-up period, \pm SD, y

\section{Perinatal abnormality}

Congenital abnormality

Mental retardation

Head injury

Infection within 1 mo before onset

Vaccination within 1 mo before onset

Prodromal signs and symptoms

at first event, $\mathrm{n}(\%)$

Headache

Nausea

Malaise

Sleepiness

Signs and symptoms at first event, $\mathrm{n}(\%)$

Encephalopathy
Seizures
Visual loss

\section{Motor paralysis}

Gait disturbance

Sensory disturbance

Urinary disturbance

Brainstem deficit

Laboratory findings at first event

Frequency of CSF abnormalities, $n(\%)$ or $n / n(\%)$ of available patients

Cell counts $\geq 5 / \mathrm{mm}^{3}$

MBP > $102 \mathrm{pg} / \mathrm{mL}$

IgG index $>0.73$

Presence of OCBs

MRI findings at first event

No. of cerebral lesions, $n \pm S D$

Frequency of having lesions, $\mathrm{n}(\%)$ or $n / n(\%)$ of available patients

\section{Cortex}

$\begin{array}{ll}56(85) & 32(82) \\ 21 / 50(42) & 14 / 30(47) \\ 5 / 14(36) & 3 / 11(27) \\ 4 / 48(8) & 2 / 34(6)\end{array}$

41 (71)

$17 / 44$ (39)

$4 / 14$ (29)

$8 / 49$ (16)

$6.3 \pm 3.1 \quad 4.8 \pm 2.9$

$28 / 61(46) \quad 12 / 36(33)$

$41 / 61$ (67)

20/31 (30)

$11 / 61$ (18)
23/39 (59)

10/36 (26)

$3 / 36$ (8)

\section{$5.7+2.9$}

$\begin{aligned} & \text { MS } \\ & (\mathbf{n}=58)\end{aligned}$
$0.53: 1$
$8.3 \pm 0.48$
$6.2 \pm 0.5$
$3(5)$
$1(2)$
1 (2)
8 (14)
2 (3)
NA
NA

NMO

(n=10)

$0.25: 1$

$10.3 \pm 1.2$

$5.3 \pm 0.73$

2 (20)

1 (10)

1 (10)

3 (30)

1 (10)

NA

NA

NA
NA
NA
NA
NA
NA

NA
NA
NA
NA
NA
NA

$1(50)$

0 (0)

$0(0)$

0 (0)

$0(0)$

0 (0)

4 (7)

2 (20)

0 (0)

5 (50)

3 (30)

4 (40)

3 (30)

3 (30)

2 (20)

(n = 2)

$0(0)$

1 (50)

1 (50)

$1(50)$

$1(50)$

$0(0)$
MDEM

( $\mathrm{n}=7$ )

Myelitis

( $\mathrm{n}=11$ )

1.0:1 $\quad 0.75: 1 \quad 1.2: 1$

$5.9 \pm 1.2$

$7.5 \pm 1.0$

$7.5 \pm 1.8$

$5.5 \pm 1.6$

$2.6 \pm 0.28$

$\begin{array}{lll}0(0) & 1(14) & 0(0) \\ 0(0) & 0(0) & 1(9) \\ 0(0) & 0(0) & 0(0) \\ 0(0) & 1(14) & 2(18) \\ 0(0) & 0(0) & 0(0) \\ 1(50) & 2(29) & 4(36) \\ 0(0) & 1(14) & 1(9)\end{array}$

(14)

(9)

White matter

Juxtacortical

$\geqq 3$ periventricular

Corpus callosum

$3.0 \pm 2.4$

$6.5 \pm 2.5$

$72+10$

$5.3 \pm 2.3$

$10(100)$

$4 / 9$ (44)

$0 / 5(0)$

1/2 (50)

$3 / 6(50)$

7 (64)

$1 / 9$ (11)

0/0 (0)

0/0 (0)

5/6 (83)

$1 / 2$ (50)

0/7 (0) 


\begin{tabular}{|c|c|c|c|c|c|c|c|}
\hline Continued & & & & & & & \\
\hline & $\begin{array}{l}\text { ADEM } \\
(n=66)\end{array}$ & $\begin{array}{l}\text { Multifocal } \\
\text { CIS ( }=39 \text { ) }\end{array}$ & $\begin{array}{l}\text { MS } \\
(n=58)\end{array}$ & $\begin{array}{l}\text { NMO } \\
(n=10)\end{array}$ & $\begin{array}{l}\text { RDEM } \\
(\mathrm{n}=2)\end{array}$ & $\begin{array}{l}\text { MDEM } \\
(\mathrm{n}=7)\end{array}$ & $\begin{array}{l}\text { Myelitis } \\
(\mathrm{n}=11)\end{array}$ \\
\hline Cerebellum & 20/66 (30) & 12/39 (31) & $16 / 58(28)$ & $3 / 10(30)$ & $1 / 2(50)$ & $3 / 7(43)$ & 1/11 (9) \\
\hline Brainstem & 19/66 (29) & $17 / 39(44)$ & 21/58 (36) & $6 / 10(60)$ & $1 / 2(50)$ & $4 / 7(57)$ & $1 / 11$ (9) \\
\hline Spinal cord & 16/42 (38) & 14/39 (36) & $13 / 42$ (31) & $9 / 10(90)$ & 0/2 (0) & 0/5 (0) & $10 / 11(91)$ \\
\hline \multicolumn{8}{|l|}{ Treatment, n (\%) } \\
\hline High-dose methyl PSL & $56(85)$ & $36(92)$ & $37(64)$ & $7(70)$ & $2(100)$ & $7(100)$ & $10(91)$ \\
\hline Oral PSL alone & $3(5)$ & $0(0)$ & 22 (38) & $5(50)$ & $0(0)$ & $0(0)$ & $0(0)$ \\
\hline Interferon beta & $0(0)$ & $0(0)$ & 19 (33) & $5(50)$ & $0(0)$ & $0(0)$ & $0(0)$ \\
\hline Frequency of sequelae, $n(\%)$ & $11(17)$ & $8(21)$ & $29(50)$ & $7(70)$ & $1(50)$ & $4(57)$ & $3(27)$ \\
\hline
\end{tabular}

Abbreviations: ADEM = acute disseminated encephalomyelitis; CIS = clinically isolated syndrome; IVIg = IV immunoglobulin; MBP = myelin basic protein; MDEM = multiphasic disseminated encephalomyelitis; $\mathrm{MS}=$ multiple sclerosis; $\mathrm{NA}=$ not available; $\mathrm{NMO}=$ neuromyelitis optica; OCB = oligoclonal band; $\mathrm{PSL}=$ prednisolone; $\mathrm{RDEM}$ = recurrent disseminated encephalomyelitis.

visual disturbances was consistent with that of a previous study, which reported that visual disturbances are a prognostic factor for future MS diagnosis in children presenting with CNS demyelination, and could be considered a risk for a second demyelinating event. ${ }^{23}$

Laboratory and MRI findings of pediatric Japanese patients with ADEM were similar to those of patients with MS at the first event, except for the presence of oligoclonal bands and optic nerve involvement. Other studies have reported that young children with MS show, at the first demyelinating event, inflammatory CSF profiles and brain MRIs similar to those of children with ADEM. ${ }^{3,24}$ Distinguishing between young children with ADEM and those with MS at the first demyelinating event is also challenging in Japan.

Pediatric MS in Japan. The estimated crude prevalence of pediatric MS in Japan was 0.69 per 100,000 children in the current study, similar to the prevalence reported in Canada and Italy $(0.56$ and 0.82 , respectively). ${ }^{25}$ This finding suggests a limited influence of ethnicity on the prevalence of pediatric MS. However, the reported prevalence of pediatric MS is highly variable. ${ }^{25}$ We found that the prevalence of pediatric MS in southern Japan tended to be lower than that in the other areas, which was also reported for adult MS in Japan. ${ }^{26}$ This suggests that where children live early in development might influence the prevalence of pediatric MS.

We compared the clinical characteristics of Japanese pediatric patients with MS to those of pediatric patients with MS from other countries (table e-2). ${ }^{3,5,6,27,28}$ The mean age at onset in Japanese pediatric patients with MS was lower than that of pediatric patients with MS from other countries. These data suggest that genetic or environmental factors might differentially affect the pathogenic processes associated with the onset of ADS according to ethnicity. In addition, we observed that the distribution of the onset age was almost even and that the sex ratio did not differ significantly between those of the earlyonset ( $<11$ years, 1:2.0 male/female ratio) and lateonset groups (1:1.7). These findings may be unique characteristics of pediatric MS in Japan.

The prevalence of seizures among patients with pediatric MS in Japan (45\%) was higher than that reported in other studies (3\% in the Netherlands and $0 \%$ in the United States). ${ }^{3,28}$ This feature was not strongly associated with age at MS onset because the prevalence of seizures in patients with MS in Japan did not differ according to age at onset (data not shown). This may be attributable to racial or regional differences in seizure susceptibility. Visual disturbances were more frequent in Japanese pediatric patients with MS at the first demyelinating event compared to those reported in other countries. This finding is similar to the results of a previous report on adult MS in Japan. ${ }^{26,29}$ Japanese pediatric patients with MS less frequently showed elevated IgG index and oligoclonal bands in the CSF compared to patients with MS in other countries. Finally, Japanese pediatric patients with MS appeared to meet Barkhof MRI criteria less frequently than those with MS in other 
Table 3 Characteristics of pediatric NMO in Japan and other countries

\begin{tabular}{|c|c|c|c|c|c|c|}
\hline & $\begin{array}{l}\text { Present study } \\
(n=10)\end{array}$ & $\begin{array}{l}\text { McKeon et al. }{ }^{30} \\
(n=58)\end{array}$ & $\begin{array}{l}\text { Banwell et al. }{ }^{31} \\
(n=17)\end{array}$ & $\begin{array}{l}\text { Lotze et al. }{ }^{32} \\
(n=9)\end{array}$ & $\begin{array}{l}\text { Huppke et al. }{ }^{33} \\
(n=6)\end{array}$ & $\begin{array}{l}\text { Collongues et al. }{ }^{34} \\
(n=12)\end{array}$ \\
\hline Country & Japan & - & Canada, Argentina & United States & Germany & France \\
\hline Criteria & $\begin{array}{l}2006 \text { NMO revised } \\
\text { criteria }\end{array}$ & $\begin{array}{l}\text { NMO-lgG } \\
\text { positive }\end{array}$ & $\begin{array}{l}2006 \text { NMO revised } \\
\text { criteria }\end{array}$ & $\begin{array}{l}2007 \text { IPMSSG } \\
\text { NMO criteria }\end{array}$ & $\begin{array}{l}2006 \text { NMO revised } \\
\text { criteria }\end{array}$ & $\begin{array}{l}2006 \text { NMO revised } \\
\text { criteria }\end{array}$ \\
\hline \multicolumn{7}{|l|}{ Demographic data } \\
\hline Male/female & $1: 4$ & $1: 7.3$ & 1:3.2 & $0: 9$ & $1: 2$ & $1: 3$ \\
\hline \multicolumn{7}{|l|}{ Race, \% } \\
\hline White & 0 & 27 & 69 & 22 & 83 & 67 \\
\hline Asian & 100 & 0 & 6 & 0 & 0 & 17 \\
\hline African American & 0 & 34 & 0 & 22 & 0 & 0 \\
\hline Turkish & 0 & 0 & 0 & 0 & 17 & 8 \\
\hline Black & 0 & 0 & 0 & 44 & 0 & 0 \\
\hline Mix (Latin American/white) & 0 & 0 & 0 & 11 & 0 & 0 \\
\hline \multicolumn{7}{|l|}{ Clinical course } \\
\hline Disease duration (range), y & 6.3 (2.3-12.3) & $1.0(0.1-10)$ & $3.0(0.1-10.5)$ & NR (0.6-9) & $3.8(0.5-8)$ & $19.3(3.7-32.7)$ \\
\hline ARR (range) & $0.66(0.2-1.7)$ & NR & NR & $2.6(1-4)$ & NR & $0.6(0.1-1.2)$ \\
\hline Monophasic/relapse & $1: 9$ & $2: 27$ & $8: 9$ & $0: 9$ & $2: 4$ & $0: 12$ \\
\hline \multicolumn{7}{|l|}{ Laboratory findings } \\
\hline
\end{tabular}

MRI findings

Brain MRI findings, \%

\begin{tabular}{|c|c|c|c|c|c|c|}
\hline$\geq 1$ lesion & 90 & 68 & 53 & 100 & 50 & NR \\
\hline Mean no. of lesions & 3 & NR & NR & NR & NR & 2 \\
\hline Juxtacortical lesion & 33 & 16 & NR & 56 & NR & NR \\
\hline Basal ganglia/thalamus & 33 & 13 & 6 & NR & NR & NR \\
\hline Corpus callosum & 0 & 5 & 6 & 44 & NR & NR \\
\hline Brainstem & 60 & NR & 38 & 78 & NR & NR \\
\hline Optic nerve & 40 & 34 & NR & 89 & NR & NR \\
\hline \multicolumn{7}{|l|}{ Spinal cord MRI findings, \% } \\
\hline$\geq 1$ T2 lesion & 90 & NR & 100 & 100 & 83.3 & NR \\
\hline LESCL & 90 & NR & 100 & 100 & NR & NR \\
\hline \multicolumn{7}{|l|}{ Jutcomes } \\
\hline EDSS, median (range) & $0.5(0-6)$ & $4.0(0-9)$ & $2.5(0-8)$ & $3(0-8)$ & NR & NR \\
\hline \multicolumn{7}{|l|}{ Mobility, \% } \\
\hline Normal & 70 & 56 & 88 & NR & NR & NR \\
\hline
\end{tabular}

Continued 
Table 3 Continued

\begin{tabular}{|c|c|c|c|c|c|c|}
\hline & $\begin{array}{l}\text { Present study } \\
(n=10)\end{array}$ & $\begin{array}{l}\text { McKeon et al. }{ }^{30} \\
(n=58)\end{array}$ & $\begin{array}{l}\text { Banwell et al. }{ }^{31} \\
(\mathrm{n}=17)\end{array}$ & $\begin{array}{l}\text { Lotze et al. } .^{32} \\
(n=9)\end{array}$ & $\begin{array}{l}\text { Huppke et al. } \\
(n=6)\end{array}$ & $\begin{array}{l}\text { Collongues et al. }{ }^{34} \\
(n=12)\end{array}$ \\
\hline Limitation, cane/aids not required & 10 & & 6 & NR & & NR \\
\hline $\begin{array}{l}\text { Wheelchair, intermittently walks } \\
\text { short distance }\end{array}$ & 10 & 44 & 0 & NR & $3 / 6(50)$ & NR \\
\hline Wheelchair-dependent & 0 & & 6 & NR & & NR \\
\hline Death & 0 & 0 & 0 & NR & & NR \\
\hline No information & 10 & NR & 0 & NR & 0 & NR \\
\hline \multicolumn{7}{|l|}{ Vision, \% } \\
\hline Normal & 60 & 46 & 29 & NR & NR & NR \\
\hline $\begin{array}{l}\text { Decreased, no limitation in daily } \\
\text { activities }\end{array}$ & 30 & 54 & 47 & NR & NR & NR \\
\hline Severe impairment & 10 & & 24 & NR & NR & NR \\
\hline No functional vision & 0 & & 0 & NR & NR & NR \\
\hline
\end{tabular}

Abbreviations: ARR = annual relapse rate; EDSS = Expanded Disability Status Scale; IgG = immunoglobulin G; IPMSSG = International Pediatric Multiple Sclerosis Study Group; LESCL = longitudinally extensive spinal cord lesions; NMO = neuromyelitis optica; NR = not recorded; OCB = oligoclonal band.

countries. These findings are also true for adult patients with MS in Japan. ${ }^{26,29}$

Pediatric NMO in Japan. We estimated the crude prevalence of pediatric NMO in Japan to be 0.06 per 100,000 children, which may be lower than the true prevalence because of the low testing rate for aquaporin-4 (AQP4) antibodies. In the present study, we identified 27 patients with both myelitis and optic neuritis, including 16 who were not tested for the AQP4 antibody. Future studies should estimate the prevalence of pediatric NMO with full examination of AQP4 antibodies.

Table 3 presents a comparison of Japanese pediatric patients with NMO to those reported in other studies. ${ }^{30-34}$ All but 2 of these previous reports ${ }^{30,32}$ used the 2006 NMO diagnostic criteria. ${ }^{22}$ The median follow-up period varied from 1.0 to 19.3 years. The mean age at onset of pediatric patients with $\mathrm{NMO}$ in Japan appeared to be lower than that of pediatric patients with NMO in other countries. However, this result might have been influenced by differences in the target age of patients with NMO included in each study. There were no apparent differences in NMO-IgG prevalence rates, but the mean CSF cell count and percentage of patients with pleocytosis were higher in pediatric patients with NMO in Japan than that in other countries. These findings may suggest differences in CNS inflammation between Japanese patients and those of other ethnicities. Finally, there were no significant differences in MRI characteristics among previous studies, including the present survey, compared to findings in other countries and adult patients with NMO..$^{35}$ This finding may support the pathogenic role of NMO-IgG because lesion distribution was closely associated with expression of AQP4, the target of NMO-IgG. ${ }^{36}$
Limitations. The present study had several limitations. First, not all medical facilities responded to our survey; thus, our dataset does not include all patients with pediatric ADS in Japan. However, the response rate was relatively high, and response biases were limited because the response rates did not vary according to hospital size and location. In addition, the results of our complete preliminary survey conducted in a limited area of Japan were compatible with those of the present study. ${ }^{17}$

The collected patient data in the present study were based on questionnaire responses, so the reliability could be uneven. However, these data were mostly collected by professional hospitals, which may enhance the reliability.

We did not investigate pediatric patients with solitary optic neuritis who visited only ophthalmologists. Hence, neither the epidemiologic nor demographic features of total CIS or NMO spectrum disorder could be analyzed. Nonetheless, patients with multifocal CIS as well as those with myelitis were included in the survey.

The results of this nationwide survey were based on the 2007 IPMSSG definitions. Therefore, the results might change based on the 2012 IPMSSG definitions. In particular, the number of patients with MS may increase. The revised definitions allow for a diagnosis of MS in patients with one demyelinating event, including those who had ever had a diagnosis of ADEM.

\section{AUTHOR CONTRIBUTIONS}

Y. Yamaguchi: study design and conceptualization, data acquisition, analysis, and interpretation, and manuscript drafting. H. Torisu: statistical analysis, data interpretation, and manuscript drafting. R. Kira: study design and conceptualization and data acquisition, analysis, and interpretation. Y. Ishizaki: data acquisition, analysis, and interpretation. Y. Sakai: manuscript drafting. M. Sanefuji: data analysis and interpretation. 
T. Ichiyama: study design and conceptualization as well as data acquisition. A. Oka: study design and conceptualization as well as data acquisition. T. Kishi: study design and conceptualization as well as data acquisition. S. Kimura: study design and conceptualization as well as data acquisition. M. Kubota: study design and conceptualization as well as data acquisition. J. Takanashi: study design and conceptualization as well as data acquisition. Y. Takahashi: study design and conceptualization as well as data acquisition. H. Tamai: study design and conceptualization as well as data acquisition. J. Natsume: study design and conceptualization as well as data acquisition. S. Hamano: study design and conceptualization as well as data acquisition. S. Hirabayashi: study design and conceptualization as well as data acquisition. Y. Maegaki: study design and conceptualization as well as data acquisition. M. Mizuguchi: study design and conceptualization as well as data acquisition. K. Minagawa: study design and conceptualization as well as data acquisition. H. Yoshikawa: study design and conceptualization as well as data acquisition. J. Kira: study design and conceptualization as well as critical manuscript revision. S. Kusunoki: study design and conceptualization as well as critical manuscript revision. T. Hara: study design and conceptualization as well as critical manuscript revision.

\section{ACKNOWLEDGMENT}

The authors thank the Japanese Pediatric Autoimmune Encephalitis research group for their advice on translating the 2007 IPMSSG definitions.

\section{STUDY FUNDING}

This work was supported in part by a Health and Labour Sciences Research Grant on Intractable Diseases (Neuroimmunological Diseases) from the Ministry of Health, Labour and Welfare of Japan as well as a Grant-in-Aid for Scientific Research from the Ministry of Education, Culture, Sports, Science and Technology of Japan.

\section{DISCLOSURE}

Y. Yamaguchi reports no disclosures relevant to the manuscript. $\mathrm{H}$ Torisu received speaker honoraria from Astellas Pharma Inc., the Japan Society for the Promotion of Science KAKENHI grant 23591503 and grants of the Ministry of Health, Labour and Welfare for research on rare and intractable diseases. R. Kira reports no disclosures relevant to the manuscript. Y. Ishizaki received the Japan Society for the Promotion of Science KAKENHI grants 23591502 and 26461547. M. Sanefuji received the Japan Society for the Promotion of Science KAKENHI grants 24791068 and 26893189. Y. Sakai, M. Sanefuji, and T. Ichiyama report no disclosures relevant to the manuscript. A. Oka serves on an editorial board for Pediatrics International, is funded by Japanese Health Labour Sciences Research grants and grant-in-aid for scientific research (23591515), and received research support from Maruho Inc. and Japan Blood Products Organization. T. Kishi is funded by a grant from the Morinaga Houshi-Kai Foundation. S. Kimura and M. Kubota report no disclosures relevant to the manuscript. J. Takanashi received a grant-inaid for scientific research (B24390258, C-24591790) from the Japan Society for the Promotion of Science, and a grant-in-aid for the research on measures for intractable diseases (H23-Nanchi-Ippan-078, H24Nanchi-Ippan-072, and H25-Nanchi-Ippan-009) and research grant for nervous and mental disorders (24-7), both from the Ministry of Health, Labour and Welfare of Japan. Y. Takahashi was supported by grants-inaid for scientific research I 21591342, 23591238, and 24591537; grants from the Ministry of Health, Labour and Welfare for comprehensive research on disability health and welfare; grants from the Ministry of Health, Labour and Welfare for research on rare and intractable diseases; grants from the National Hospital Organization, and grants from the Japan Epilepsy Research Foundation. H. Tamai received research support from Nobel Pharma. J. Natsume reports no disclosures relevant to the manuscript. S. Hamano received research support from Novartis Pharmaceuticals, Japan, and Alfresa Pharma Corporation. S. Hirabayashi and Y. Maegaki report no disclosures relevant to the manuscript. M. Mizuguchi received honoraria for serving on the scientific advisory board of Novartis Pharmaceuticals, and is funded by the Japan Society for the Promotion of Science grants 24390258 and 24659490, and by Ministry of Health, Labour and Welfare grants H25-Nanji-Ippan-009 and
H25-Jisedai-Ippan-004. K. Minagawa and H. Yoshikawa report no disclosures relevant to the manuscript. J. Kira is an advisory board member for Merck Serono and a consultant for Biogen Idec, Japan. He has received payment for lectures from Bayer Schering Pharma, Cosmic Corporation, and Biogen Idec, Japan. S. Kusunoki serves as an editorial board member of Experimental Neurology, Journal of Neuroimmunology, and Neurology \& Clinical Neuroscience (associate editor). He received honoraria from Teijin Pharma, Nihon Pharmaceuticals, Japan Blood Products Organization, Novartis, Dainippon Sumitomo Pharma, Kyowa Kirin, Asahi Kasei, Bayer, Sanofi, and GlaxoSmithKline. He is funded by research grants from the Ministry of Health, Labour and Welfare, Japan, and grants from the Japan Science and Technology Agency and the Ministry of Education, Culture, Sports, Science and Technology, Japan. He received research support from GlaxoSmithKline, Dainippon Sumitomo Pharma, Teijin Pharma, Astellas, Novartis, Sanofi, Japan Blood Products Organization, and Nihon Pharmaceuticals. T. Hara reports no disclosures relevant to the manuscript. Go to Neurology.org for full disclosures.

Received October 21, 2014. Accepted in final form July 28, 2016.

\section{REFERENCES}

1. Krupp LB, Banwell B, Tenembaum S; International Pediatric MS Study Group. Consensus definitions proposed for pediatric multiple sclerosis and related disorders. Neurology 2007;68:S7-S12.

2. Mikaeloff Y, Suissa S, Vallee L, et al. First episode of acute CNS inflammatory demyelination in childhood: prognostic factors for multiple sclerosis and disability. J Pediatr 2004; 144:246-252.

3. Neuteboom RF, Boon M, Catsman Berrevoets CE, et al. Prognostic factors after a first attack of inflammatory CNS demyelination in children. Neurology 2008;71:967-973.

4. Banwell B, Kennedy J, Sadovnick D, et al. Incidence of acquired demyelination of the CNS in Canadian children. Neurology 2009;72:232-239.

5. Ketelslegers IA, Neuteboom RF, Boon M, CatsmanBerrevoets CE, Hintzen RQ; Dutch Pediatric MS Study Group. A comparison of MRI criteria for diagnosing pediatric ADEM and MS. Neurology 2010;74:1412-1415.

6. Banwell B, Bar-Or A, Arnold DL, et al. Clinical, environmental, and genetic determinants of multiple sclerosis in children with acute demyelination: a prospective national cohort study. Lancet Neurol 2011;10:436-445.

7. Langer-Gould A, Zhang JL, Chung J, Yeung Y, Waubant E, Yao J. Incidence of acquired CNS demyelinating syndromes in a multiethnic cohort of children. Neurology 2011;77: $1143-1148$.

8. Banwell B, Shroff M, Ness JM, et al. MRI features of pediatric multiple sclerosis. Neurology 2007;68:S46-S53.

9. Leake JA, Albani S, Kao AS, et al. Acute disseminated encephalomyelitis in childhood: epidemiologic, clinical and laboratory features. Pediatr Infect Dis J 2004;23:756-764.

10. Pohl D, Hennemuth I, von Kries R, Hanefeld F. Paediatric multiple sclerosis and acute disseminated encephalomyelitis in Germany: results of a nationwide survey. Eur J Pediatr 2007;166:405-412.

11. Ketelslegers IA, Catsman-Berrevoets CE, Neuteboom RF, et al. Incidence of acquired demyelinating syndromes of the CNS in Dutch children: a nationwide study. J Neurol 2012;259:1929-1935.

12. Absoud M, Lim MJ, Chong WK, et al. Paediatric acquired demyelinating syndromes: incidence, clinical and magnetic resonance imaging features. Mult Scler 2013;19:76-86.

13. Hung KL, Liao HT, Tsai ML. The spectrum of postinfectious encephalomyelitis. Brain Dev 2001;23:42-45. 
14. Shiraishi K, Higuchi Y, Ozawa K, Hao Q, Saida T. Clinical course and prognosis of 27 patients with childhood onset multiple sclerosis in Japan. Brain Dev 2005;27:224-227.

15. Singhi PD, Ray M, Singhi S, Kumar Khandelwal N. Acute disseminated encephalomyelitis in North Indian children: clinical profile and follow-up. J Child Neurol 2006;21:851-857.

16. Weng WC, Yang CC, Yu TW, Shen YZ, Lee WT. Multiple sclerosis with childhood onset: report of 21 cases in Taiwan. Pediatr Neurol 2006;35:327-334.

17. Torisu H, Kira R, Ishizaki Y, et al. Clinical study of childhood acute disseminated encephalomyelitis, multiple sclerosis, and acute transverse myelitis in Fukuoka Prefecture, Japan. Brain Dev 2010;32:454-462.

18. Visudtibhan A, Tuntiyathorn L, Vaewpanich J, et al. Acute disseminated encephalomyelitis: a 10-year cohort study in Thai children. Eur J Paediatr Neurol 2010;14:513-518.

19. Hung PC, Wang HS, Chou ML, Lin KL, Hsieh MY, Wong AM. Acute disseminated encephalomyelitis in children: a single institution experience of 28 patients. Neuropediatrics 2012;43:64-71.

20. Nakamura Y, Matsumoto T, Tamakoshi A, et al. Prevalence of idiopathic hypoparathyroidism and pseudohypoparathyroidism in Japan. J Epidemiol 2000;10:29-33.

21. Kuriyama S, Kusaka Y, Fujimura M, et al. Prevalence and clinicoepidemiological features of moyamoya disease in Japan: findings from a nationwide epidemiological survey. Stroke 2008;39:42-47.

22. Wingerchuk DM, Lennon VA, Pittock SJ, Lucchinetti CF, Weinshenker BG. Revised diagnostic criteria for neuromyelitis optica. Neurology 2006;66:1485-1489.

23. Mikaeloff Y, Caridade G, Husson B, Suissa S, Tardieu M; Neuropediatric KIDSEP Study Group of the French Neuropediatric Society. Acute disseminated encephalomyelitis cohort study: prognostic factors for relapse. Eur J Paediatr Neurol 2007;11:90-95.

24. Chabas D, Ness J, Belman A, et al. Younger children with MS have a distinct CSF inflammatory profile at disease onset. Neurology 2010;74:399-405.
25. Multiple Sclerosis International Federation. Atlas of MS. Available at: www.msif.org/about-us/adovocacy/atlas. Accessed June 19, 2016.

26. Kira J. Multiple sclerosis in the Japanese population. Lancet Neurol 2003;2:117-127.

27. Atzori M, Battistella PA, Perini P, et al. Clinical and diagnostic aspects of multiple sclerosis and acute monophasic encephalomyelitis in pediatric patients: a single centre prospective study. Mult Scler 2009;15:363-370.

28. Alper G, Heyman R, Wang L. Multiple sclerosis and acute disseminated encephalomyelitis diagnosed in children after long-term follow-up: comparison of presenting features. Dev Med Child Neurol 2009;51:480-486.

29. Osoegawa M, Kira J, Fukazawa T, et al. Temporal changes and geographical differences in multiple sclerosis phenotypes in Japanese: nationwide survey results over 30 years. Mult Scler 2009;15:159-173.

30. McKeon A, Lennon VA, Lotze T, et al. CNS aquaporin-4 autoimmunity in children. Neurology 2008;71:93-100.

31. Banwell B, Tenembaum S, Lennon VA, et al. Neuromyelitis optica-IgG in childhood inflammatory demyelinating CNS disorders. Neurology 2008;70:344-352.

32. Lotze TE, Northrop JL, Hutton GJ, Ross B, Schiffman JS, Hunter JV. Spectrum of pediatric neuromyelitis optica. Pediatrics 2008;122:e1039-e1047.

33. Huppke P, Bluthner M, Bauer O, et al. Neuromyelitis optica and NMO-IgG in European pediatric patients. Neurology 2010;75:1740-1744.

34. Collongues N, Marignier R, Zephir H, et al. Neuromyelitis optica in France: a multicenter study of 125 patients. Neurology 2010;74:736-742.

35. Pittock SJ, Lennon VA, Krecke K, Wingerchuk DM, Lucchinetti CF, Weinshenker BG. Brain abnormalities in neuromyelitis optica. Arch Neurol 2006;63:390-396.

36. Pittock SJ, Weinshenker BG, Lucchinetti CF, Wingerchuk DM, Corboy JR, Lennon VA. Neuromyelitis optica brain lesions localized at sites of high aquaporin 4 expression. Arch Neurol 2006;63:964-968.

\section{㹣 Neurology.org Offers Important Information to Patients and Their Families}

The Neurology ${ }^{\circledR}$ Patient Page provides:

- A critical review of ground-breaking discoveries in neurologic research that are written especially for patients and their families

- Up-to-date patient information about many neurologic diseases

- Links to additional information resources for neurologic patients

All Neurology Patient Page articles can be easily downloaded and printed, and may be reproduced to distribute for educational purposes. Click on the 'Patients' link on the home page (Neurology.org) for a complete index of Patient Pages. 


\section{Neurology}

\section{A nationwide survey of pediatric acquired demyelinating syndromes in Japan}

Y. Yamaguchi, H. Torisu, R. Kira, et al.

Neurology 2016;87;2006-2015 Published Online before print October 14, 2016

DOI 10.1212/WNL.0000000000003318

\section{This information is current as of October 14, 2016}

\section{Updated Information \& Services}

\section{Supplementary Material}

\section{References}

\section{Citations}

\section{Subspecialty Collections}

Permissions \& Licensing

\section{Reprints}

including high resolution figures, can be found at: http://n.neurology.org/content/87/19/2006.full

Supplementary material can be found at: http://n.neurology.org/content/suppl/2016/10/14/WNL.0000000000003 318.DC1

This article cites 35 articles, 13 of which you can access for free at: http://n.neurology.org/content/87/19/2006.full\#ref-list-1

This article has been cited by 2 HighWire-hosted articles: http://n.neurology.org/content/87/19/2006.full\#\#otherarticles

This article, along with others on similar topics, appears in the following collection(s):

All Clinical Neurology http://n.neurology.org/cgi/collection/all_clinical_neurology All Demyelinating disease (CNS)

http://n.neurology.org/cgi/collection/all_demyelinating_disease_cns All epidemiology

http://n.neurology.org/cgi/collection/all_epidemiology

\section{All Pediatric}

http://n.neurology.org/cgi/collection/all_pediatric

Information about reproducing this article in parts (figures,tables) or in its entirety can be found online at:

http://www.neurology.org/about/about_the_journal\#permissions

Information about ordering reprints can be found online:

http://n.neurology.org/subscribers/advertise

Neurology ${ }^{\circledR}$ is the official journal of the American Academy of Neurology. Published continuously since 1951, it is now a weekly with 48 issues per year. Copyright () 2016 American Academy of Neurology. All rights reserved. Print ISSN: 0028-3878. Online ISSN: 1526-632X.

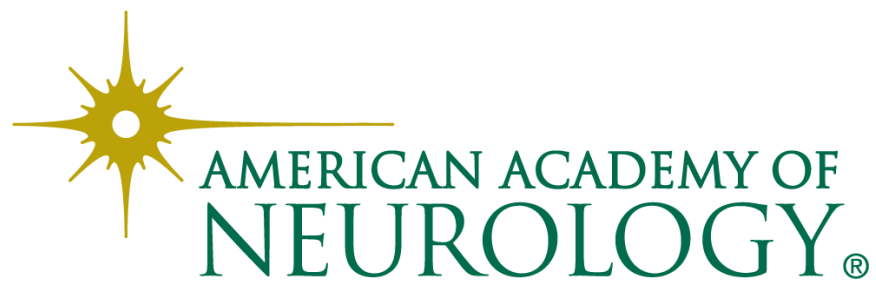

